\title{
ANÁLISE DE UMA NARRATIVA SOBRE LEITURA E ESCRITA EM LINGUA INGLESA
}

\author{
Mônica Veloso Borges ${ }^{1}$ \\ Luís Miguel Gordiano Ramos ${ }^{2}$
}

\begin{abstract}
Resumo:
Este relato de experiência visa apresentar o resultado de um projeto de ensino e aprendizagem de leitura e escrita em língua inglesa (LI), desenvolvido no âmbito do PIBID da UNEB/Campus XIV na cidade de Conceição do Coité/Ba. O projeto foi executado em duas instituições públicas de ensino básico da região. A principal motivação, para a execução deste projeto, foià identificação, através de pesquisas realizadas em produções de TCCs, do foco gramatical como única metodologia utilizada em sala de aula nas escolas básicas da região. Neste sentido, foi proposto uma intervenção do PIBID que teve como um dos objetivosrefletir sobre o ensino da escrita e de leitura em LI tendo como base o letramento crítico, através da narrativa do bolsista MiguelGordiano Ramos.
\end{abstract}

Palavras-chave: PIBID, formação docente, ensino de leitura e escrita, língua inglesa.

Introdução

Este relato de experiência versa sobre o projeto de ensino e aprendizagem de leitura e escrita em língua inglesa, promovido pelo PIBID da UNEB/ Campus XIV na cidade de Conceição do Coité/ Ba. Tal projeto se realiza em duas instituições do ensino básico da região, tendo como participantes duas coordenadoras de área, duas supervisoras e vinte e dois bolsistas da graduação em Língua Inglesa deste Campus.

Nossa metodologia de trabalho, como coordenadoras no processo de formação na orientação aos alunos bolsistas, se divide em duas frentes. A primeira está voltada para o estudo da língua inglesa (doravante LI) e aperfeiçoamento da escrita e da leitura dos estudantes bolsistas, com base em leitura crítica e interpretação de textos de gêneros diversos e desenvolvimento da escrita como exercício contínuo. A segunda frente, cuja dinâmica servirá como objeto de relato e análise nas páginas que se seguem, tem como princípio a teorização metodológica do processo de ensino e aprendizagem da leitura e escrita críticas de textos e a sua articulação com a prática nas escolas de ensino básico ${ }^{3}$ da região.

\footnotetext{
${ }^{1}$ Mestre em Língua e Cultura pela Universidade Federal da Bahia (UFBA). Atua como professora/orientadora da disciplina Estágio Supervisionado na Universidade do Estado da Bahia (UNEB)/ Campus XIV. moveraes@yahoo.com.br

${ }^{2}$ Luís Miguel Gordiano Ramos. Graduando do curso de Letras Língua Inglesa e Respectivas Literaturas. Campus XIV da Universidade do Estado da Bahia (UNEB). miguel gordiano1@ hotmail.com

${ }^{3} \mathrm{O}$ nosso trabalho tem como público-alvo os alunos de Ensino Médio de duas escolas básicas da cidade de Conceição do Coité.
} 
Temos, ao longo do decorrer do projeto ${ }^{4}$, discutido sobre vários temas com os alunos, não só no que tange as metodologias de ensino de sala de aula, como também na valorização da disciplina, no ensino de $\mathrm{LI}$ e no caráter educativo que envolve o ensino de língua inglesa neste mundo influenciado por tecnologias e, consequentemente, pela aproximação das fronteiras culturais. Utilizamos o conceito de caráter educativo desenvolvido por Jorge (2009, p. 163) quando esta afirma que:

O caráter educativo do ensino de uma língua estrangeira está na possibilidade que o aluno pode ter de se tornar mais consciente da diversidade que constitui o mundo. As múltiplas possibilidades de ser diferente, seja pela cultura, sejam pelas identidades individuais, podem fazer com que o indivíduo se torne mais consciente de si próprio, em relação a seu contexto local e ao contexto global (JORGE, 2009, p.163).

O objetivo é mostrar como a teoria se articula com a prática em contextos de ensino real em escolas públicas da região de Conceição do Coité. Para tanto, vamos exporalgumas teorias que fundamentam a nossa prática e uma atividade de letramento crítico desenvolvida pelos alunos bolsistas em parceria com a supervisora e descrita por Miguel Gordiano, aluno bolsista do programa.

O fato que motivou o planejamento e a execução do projeto se deu a partir de leituras de diversos TCCs ${ }^{5}$ dos alunos da graduação, em que foi possível identificar, como principal problema, o ensino de LI focado, exclusivamente, na gramática. As quatro habilidades, na maioria das vezes, foram negligenciadas em prol do ensino de normas descontextualizadas, não levando em conta o poder educativo e cultural que envolve o ensino destas. Diante deste quadro e pensando na necessidade, inicialmente, de aprimorarmos algumas habilidades, tendo como meta o ENEM e o vestibular para os alunos do Ensino Médio, escolhemos como foco o ensino das habilidades de leitura e escrita, com ênfase na reflexão crítica.

Portanto, acreditamos que o ensino de uma língua estrangeira deva ser focado em toda sua capacidade comunicativa e no ensino das quatro habilidades sem negar, entretanto, as necessidades dos alunos das escolas de ensino médio da região. Consequentemente, a necessidade mais latente foi o desenvolvimento da escrita e leitura críticas desses alunos.A formação teórica foi realizada de forma sequenciada e progressiva, pela necessidade de se construir juntos, (supervisores ${ }^{6}$, professores e bolsistas) metodologias diversas que caracterizassem a construção de saberes e de crenças sobre aprendizagem e ensino de língua inglesa.

\footnotetext{
${ }^{4}$ Referimos-nos aqui ao processo de orientação da prática dos bolsistas.

${ }^{5}$ Estes TCCs foram fundamentados em pesquisas em linguística aplicada, em que o foco principal foi pesquisar contextos reais de ensino nas escolas básicas.

${ }^{6}$ Gostaríamos de agradecer a professora supervisora Elisângela Martins pela ajuda nas informações e pelo seu excelente trabalho na orientação dos alunos bolsistas do PIBID.
} 
1- Pressuposto teórico

O embasamento teórico para a execução do projeto foi gradual e se fez uso, inicialmente ${ }^{7}$, de autores como Tomitch (2009), Paiva (2007), Janzen (2009), Oliveira (2015) dentre outros. Assim,focamos em metodologias que detalhassem e abrissem discussões de como ensinar tal habilidade de forma contextualizada e significativa, com dicas de atividades e debates sobre abordagens mais significativas para o contexto dos alunos das escolas básicas. O trabalho foi se fortalecendo de maneira progressiva.Neste sentido, visando aarticulação entre teoria e prática, provocamos a aproximação entre os pressupostos teóricos e a ação deformulação de planos de aulas elaborados pelos bolsistas.

No que se refere à dinâmica do debate teórico, o mesmo se concretizou na discussão em torno das etapas de uma aula de leitura que consistiramem dividir a aula em três momentos importantes, a saber: pré-leitura, leitura e pós-leitura. Inspirados em Tomitch (2009), identificamos que a leitura deve ser vista como um momento de abertura para novos conhecimentos e debates sobre novas perspectivas culturais, tornando-se uma ferramenta alternativa para que alunos de escola básica tenham capacidade de exercer sua cidadania.

Ainda na perspectiva de provocar o diálogo entre a teoria e a ação - representada na formulação de planejamentos - abordamos a habilidade escrita, tema que tem se constituído entre os mais desafiadores pela tamanha resistência e dificuldades dos alunos de escola básica. A motivação principal que definiu nossa linha de atuação partiu da premissa de que a compreensão do ensino de escrita está atrelada ao conhecimento de várias habilidades como a leitura de gêneros e temas diversos, a aquisição de vocabulário, conhecimento de mundo e a organização de ideias, (SILVA \& JORGES, 2005; COSTA, 2012; RAIMES, 2009; AMARAL, 2015). O trabalho inicial se mostrou, até certo ponto, desafiador, na medida em que nos exigiuum esforço de conscientização e modificação de uma metodologia tecnicista e estrutural que de certa forma ainda perdura no cotidiano das escolas básicas.

O tema da escrita tende a nos aproximar de um pensamento crítico e dialogar diretamente com o debate teórico pertinente a essa linha de pensamento. De acordo com Giroux (1997) dois pontos básicos constituem o pensamento crítico: de um ladoo relacionamento entre teoria e fatos e, de outro,a evidência de que o conhecimento não pode estar desassociado de interesses, normas e valores humanos. Aqui, neste momento, trata-se de lidar com informações, não como meros dados,

\footnotetext{
7 Justificamos aqui que foi inicialmente, pois percebemos que os bolsistas precisavam discutir o processo de ensino e aprendizagem de LI desde sua concepção.
} 
mas com o objetivo de problematizá-la ${ }^{8}$ dentro do contexto pedagógico que leve à formação do pensamento crítico, assim "o conhecimento, neste caso, exige busca, invenção e reinvenção constantes" (GIROUX, 1997 p.99).

Giroux (1997) nos leva a interrogar - quando se refere à construção do pensamento crítico e à influência de seu contexto social - onde estão os interesses, valores e princípios, necessários a levar os estudantes a se sentirem capazes de saírem de seu próprio sistema de referência, de forma que possam questionar a legitimidade de um determinado fato, conceito ou questão. Eles também precisam perceber a própria essência daquilo que estão examinando, analisando o conteúdo criticamente em um sistema de relacionamentos que Ihe empreste significado (GIROUX, 1997, p. 100).

Entendemos que subjacente ao pensamento de Giroux, encontra-se a ideia de que o desenvolvimento do pensamento dialético proporciona uma pedagogia crítica e leva o estudante a fazer conexões e reflexões sobre os fatos, gerando, neste sentido, a construção de um conhecimento mais amplo e articulado. Tal pensamento crítico caminha por meios distantes do pensamento isolado e compartimentado, como o conhecimento tecnicista pressupõe. Percebemos, então, que o ensino da escrita deve conter esses pressupostos teóricos, em razão de não ignorar as relações sociais da sala de aula e evitar focos em trabalhos que só apresentam dados incompletos e muitas vezes baseados em senso comum. Dito isto, "a tarefa de ligar a escrita, a aprendizagem e o pensamento crítico significa redefinir a pedagogia da escrita e também do pensamento crítico" (GIROUX, 1997, p.101).

No âmbito do projeto, compartilhamos a discussão teórica sobre a diferença entre leitura e letramento, visto que para entendê-la se faz necessário reconhecermos a existência de uma distinção epistemológica entre o conhecimento cognitivo e o conhecimento sócio-cultural. Motta (2007), inspiradaem Luke e Freebody (1997) e Cervettietalli (2001), explica que ao se tratar de leitura, a abordagem cognitiva compreende que "ler é um processo natural em que o leitor aciona em sua memória esquemas cognitivos e de conhecimentos anteriores", assim, este "desvela e compreende o significado contido no texto" (MOTTA, 2007) ou seja, o conhecimento é entendido como verdadeiro, neutro e universal, fazendo com que o leitor adapte-se ao sentido expresso pelo autor.

Em outra ordem de significado o letramento na visão sócio-cultural "considera a construção de sentidos uma decorrência de práticas sociais e culturais" (MOTTA, 2007, p.10). Por isso não podemos deixar de fora o poder ideológico da linguagem. Motta (2007), dentro desse entendimento afirma que,

\footnotetext{
${ }^{8}$ Ao problematizar os dados ou conteúdos criamos, em sala de aula, um ambiente de debate em torno de temas, assim o professor deve proporcionar ao aluno a leitura de vários textos, sob perspectivas diversas, dentrode um mesmo tema, afim de obter a construção de um conhecimento significativo para os alunos.
} 
O letramento concebe a linguagem como instrumento ideológico, responsável por construir realidades e conhecimentos contingentes; portanto, cabe ao leitor negociar os sentidos construídos pelo autor do texto, não aceitando, passivamente, o seu ponto de vista como sendo o único possível (MOTTA, 2007, p. 11).

É necessário criarmos um ambiente favorável ao desenvolvimento do pensamento crítico. Aos alunos bolsistas, cabe oportunizarmos condições que possibilitem seu amadurecimento no entendimento dessas concepções teóricas ${ }^{9}$. O bolsista deve compreender o seu papel diante dos alunos da escola básica e diante das várias formas de letramento crítico existentes.

A concepção fundamental que devemos ter ao se tratar de processos de letramentos ou de formação do letramento crítico nas escolas básicas está na capacidade de entendermos a sociedade e a diversidade existente na linguagem e na sua capacidade de mudanças nos usos da língua. Dentro desta perspectiva percebemos a grande influência do fator social e individual nas conduções de práticas letradas realizadas pelos sujeitos. Assim corroboramos com Silva e Araújo (2012, p. 697):

[...] a visão de letramento como um fenômeno plural, dado o reconhecimento de que não existe apenas um tipo de letramento, mas letramentos, que surgem conforme o avanço tecnológico e o desenvolvimento da sociedade. Atrelado a isso, está o reconhecimento de diversas agências letradas - acadêmica, escolar, midiática, digital, entre outras - que se constituem a partir de eventos e práticas que as definem como tal.

É inegável o avanço tecnológico e nossa capacidade, como professores ou futuros professores, de utilizar desses meios a fim de inserir nossos alunos neste universo cultural e social que a internet proporciona. $O$ letramento se torna um fenômeno plural conectado à complexidade e à mobilidade da vida moderna. Sendo assim, o ensino de leitura e escrita está atrelado ao contexto cultural e social de cada indivíduo e cabe ao professor se empoderar com os conhecimentos específicos a fim de proporcionar aos seus alunos a capacidade de lidar com questões reflexivas em contexto social, cultural e político.

\section{2- Metodologia}

Quanto ao ato de elaboração de planejamentos, construídos de forma conjunta com os alunos bolsistas e supervisores, resultou em inúmeras atividades voltadas para o desenvolvimento do letramento crítico. Em termos de atuação prática, no cotidiano das escolas, este projeto efetuou, em2016, uma série de visitas in loco onde foi possível presenciarmos algumas construções e produções de trabalhos realizados.

${ }^{9}$ Referimo-nos as questões teóricas abordadas aqui sobre letramento crítico. 
Deste trabalho de campo ficou evidenciado a importância da pesquisa qualitativacomo meio de avaliar, reavaliar, interferir e otimizar o trabalho escolar. Assim, percebemos que das pesquisas em sala de aula decorrem o debate acerca de como melhorar o processo de ensino e aprendizagem. Em contexto real as pesquisas derivam da investigação por meio de observações, entrevistas e análises de documentos.

Corroboramos com Telles (2002, p.102) quando este argumenta que:

\begin{abstract}
Atualmente, a opção por modalidades qualitativas de investigação tem sido cada vez mais frequente na pesquisa em educação, visto que os educadores e os professores têm se interessado pelas qualidades dos fenômenos educacionais em detrimento de números que muitas vezes escondem a dimensão humana, pluralidade e interdependência dos fenômenos educacionais na escola.
\end{abstract}

Em sintonia com o conceito de modalidade qualitativa e entrando no campo da autoetnografia $^{10}$ optamos por analisar uma narrativa, baseada no desenvolvimento do letramento crítico, de autoria do bolsista Miguel Gordiano, fundamentado no projeto "inspiringstories, inspiringvalues" desenvolvido em uma das escolas cobertas pelo PIBID de Língua Inglesa da UNEB/Campus XIV. Tal projeto é descrito a partir da sua implementação até a sua culminância.

\title{
3- Análise de dados
}

3.1- Narrativa do projeto "inspiringstories, inspiringvalues" descrita pelo aluno bolsista Miguel Gordiano.

Na terceira unidade do ano letivo de 2016 um grupo de alunos do PIBID desenvolveu um projeto a partir de um capítulo do livro didático "Way togo 3" em turmas de terceiro ano do ensino médio no colégio Polivalente de Conceição do Coité - Bahia. O capítulo em questão é intitulado "InspiringStories, InspiringValues" e tem como foco abordar as questões éticas sobre valores e histórias exitosas de pessoas que superaram problemas e realidades desestimuladoras. A partir dessa ideia inicial, elaboramos uma sequência didática com uma culminância que gerou o impacto almejado nos alunos.

Realizamos como "warmup" uma atividade de interação a partir das imagens presentes na página introdutória do terceiro capítulo do livro. São quatro imagens: a primeira exibe uma deficiente visual com o seu cão-guia, a segunda apresenta um garoto em processo de recuperação de uma possivel fratura no braço, a terceira traz a relação entre mãe e filho e por fim a última imagem é

\footnotetext{
${ }^{10}$ Escolhemos a autoetnografia, pois este trabalho tanto o aluno bolsista, quantoas coordenadoras do projeto estão envolvidos diretamente e indiretamente. O bolsista esteve na escola colocando o projeto em prática e as coordenadoras se envolvem com a prática através das visitas in loco e através das discussões teóricas e formulações de planejamentos em conjunto.
} 
composta por um casal de idosos. A partir dessas imagens, questionamos os alunos: "What are thevaluesassociatedwiththepicturesbelow?" e então criou-se um ambiente de conversa informal sobre o tema em questão. Após essas discussões iniciais, apresentemos um vocabulário (presente na página 50 do livro) sobre situações de superação.

Ao planejar as atividades com um tema tão significativo, notamos a importância de trazer uma história de superação situada no contexto local dos alunos para exemplificar uma realidade próxima e contextualizar a temática trabalhada. Então apresentamos a história de Deiziane Mota através de uma entrevista que ela concedeu à uma equipe de TV estadual, na qual sua história é explorada e conhecemos a história de superação que, trocando em miúdos, narra a dificuldade de uma surda estudar em uma escola despreparada para recebê-la e a caminhada percorrida até hoje ao ter se tornado professora para alunos surdos nesta mesma escola.

Cumprindo o propósito do nosso projeto do PIBID (Avançando no inglês a partir de leitura e escrita), realizamos uma atividade de leitura proposta no livro didático que aborda a história do "Team Hoyt" (contexto global), que consiste em um pai que corre maratonas empurrando seu filho que sofreu por insuficiência respiratória quando criança e tornou-se incapaz de andar. Mas antes da leitura do texto "About Team Hoyt", exibimos um vídeo em inglês com legendas em português que apresenta a história completa dessa família, visando auxiliar os alunos no processo de leitura. Depois da leitura do texto (página 52), realizamos as atividades do livro para consolidar as informações apresentadas no texto. Orientamos a leitura através de "scanning" para que os alunos encontrassem as informações específicas solicitadas nas atividades.

Para dar continuidade às atividades do projeto, pensamos em escolher uma música que contemplasse o tema e nos auxiliasse em uma atividade de escrita. A música selecionada foi "I lived" de OneRepublic, uma banda americana. O clipe da canção é um pequeno documentário que narra a história de Bryan Warnecke que tem fibrose cística e a letra traz uma realidade positiva de superação. Entregamos a letra da música em inglês para os alunos e socializamos alguns trechos mais impactantes da canção, em especial o refrão que diz: "Hope whenthemoment comes you'llsay I did it all"11. E então solicitamos uma atividade escrita a partir do seguinte enunciado: "10 things I wanttosay "I did it all" whenthemoment comes', na qual os alunos deveriam elicitar dez metas de vida que serão lembradas no final de suas vidas.

Para a culminância do projeto, dividimos as turmas em grupos e lançamos o desafio de encontrar histórias de superação no ambiente escolar. Os alunos deveriam procurar e entrevistar pessoas dispostas a compartilhar suas vivências e alguns acontecimentos específicos que fizeram possível a superação de problemas. A apresentação do vídeo das histórias foi um excelente momento

\footnotetext{
${ }^{11}$ Tradução nossa: "Tenho esperanças de quando o momento chegar você irá dizer que fez tudo".
} 
do projeto, já que os bolsistas, professora e os alunos tomaram conhecimento de situações tão difíceis, mas que foram superadas a partir de um trabalho árduo e significante. Além da apresentação dos vídeos, cada grupo deveria escrever (APÊNDICE A), em inglês, a biografia dos entrevistados e entregá-las para a professora regente (supervisora do PIBID). Para a escrita do texto, os alunos basearam-se na biografia da Irmã Dulce que exploramos numa aula anterior.

Na última aula do projeto, apresentamos alguns esportes paralímpicos, já que as Paralimpíadas Rio 2016 estavam prestes a começar. E realizamos como dinâmica a prática do vôlei sentado $^{12}$, que é uma das modalidades do evento. Esta atividade foi muito impactante, uma vez que os alunos reportaram como foi estar, de alguma forma, no lugar do outro.

O projeto, a partir de uma visão geral, foi um divisor de águas para os envolvidos, por razão do estudo das realidades difíceis que muitas pessoas enfrentam e ainda assim conseguem ultrapassar todos os obstáculos e viver como qualquer um. Em todo o momento do projeto, enfatizamos que talvez nossos problemas nem sejam tão grandes assim: é uma questão de saber lidar com as adversidades e ter força de vontade.

\section{2- Análise da narrativa}

Iniciamos a análise da narrativa dividindo em etapas de ocorrência, justamente para demonstrar a sequência didática criada pela supervisora e pelos bolsistas. Partimos do pressuposto de que qualquer atividade deve ter um objetivo claro e significativo.O professor deve ter conhecimento do universo dos alunos da escola básica e, consequentemente, pesquisar por atividades, não só para desenvolver as habilidades linguísticas na língua alvo, mas também proporcionar um espaço para aprofundar o senso crítico destes estudantes através do letramento crítico. Neste sentido, a importância do trabalho em conjunto com a supervisora, fazendo com que o futuro professor interfira tanto na criação de projetos quanto na sua aplicação, é essencial para o aperfeiçoamento profissional e humano deste futuro professor. Segue a sequência com a análise de cada etapa:

a- A Coordenação do PIBID/LI e o debate teórico com os alunos bolsistas sobre ensino de leitura e escrita e letramento crítico

A coordenação do PIBID/ LI tem a preocupação constante da análise e do debate teórico sobre as questões que predominam o universo escolar. A dinâmica tende a basear-se no diálogo

\footnotetext{
${ }^{12}$ Os alunos tiveram que realizar o jogo sentado.
} 
entre o conteúdo teórico apresentado pelo professor e a experiência prática advinda do bolsista. Nitidamente, nas escolhas dos temas, a presença do debate teórico em sala de aula reflete diretamente na construção do conteúdo programático escolar.A descrição desta atividade possibilita a percepção da construção e efetivação do debate em torno da diversidade, do respeito, da superação dos problemas e da igualdade projetada na escolha do tema.

b- Criação de projeto em conjunto com a supervisora e os alunos bolsistas

Nesta primeira parte os bolsistas situam a escolha do projeto e a fonte de sua inspiração. Fica evidenciado tratar-se de um projeto organizado através de uma sequência didática, como podemos comprovar no trecho abaixo:

\begin{abstract}
Na terceira unidade do ano letivo de 2016 um grupo de alunos do PIBID desenvolveu um projeto a partir de um capítulo do livro didático "Way togo 3" em turmas de terceiro ano do ensino médio no colégio Polivalente de Conceição do Coité - Bahia. O capitulo em questão é intitulado "InspiringStories, InspiringValues" e tem como foco abordar as questões éticas sobre valores e histórias exitosas de pessoas que superaram problemas e realidades desestimuladoras. A partir dessa ideia inicial, elaboramos uma sequência didática com uma culminância que gerou $o$ impacto almejado nos alunos.
\end{abstract}

Observamos a organização das ideias através datomada de decisões realizada por todos os membros envolvidos com o PIBID. Os bolsistas discutem com os coordenadores do programa a base teórica e depois, juntamente com o professor supervisor, organizam suas ações. O livro didático ${ }^{13}$ serve de fonte enriquecedora de temas, oferecendo ideias de atividades e inspiração para criação de atividades originais. Ressaltamos a maneira responsável em que se deu a escolha do livro didático por parte dos professores de língua inglesa da escola em questão.

Não podemos deixar de enfatizar a importância do livro como instrumento de aprendizagem em uma sala de aula. Por outro lado, o grande desafio do professor está em utilizá-lo no limite do bom senso. O livro deve ser encarado muito mais como um organizador de conteúdos e, principalmente, como um fomentador de temas. Cabe ao professor as escolhas e das abordagens, indo além do que o livro pode oferecer. Quem deve fazer escolhas e entender as necessidades do seu grupo é o professor. A ele cabe o papel de navegar entre as atividades utilizando o livro de forma sábia. De acordo com Harmer,"o livro didático, em outras palavras, é um acréscimo (geralmente o mais importante que existe), porém não é um livro sagrado (HARMER, 2000, p. 258) ${ }^{14 ”}$.

c- Implementação do projeto com uso de aquecimento e preparação para o tema

\footnotetext{
${ }^{13}$ TAVARES, Kátia Cristina do Amaral. Way togo: língua estrangeira moderna. EnsinoMédio. EditoraÁtica. São Paulo, 2013.

${ }^{14}$ Traduçãonossa: "the textbook, in other words, is an add (often the most important one there is) and not a sacred text (HARMER, 2000, p. 258)"
} 
Do próximo trecho, emerge as estratégias iniciais da implementação do projeto e a "preparação do ambiente" para as atividades que se seguirão. Apresentar ao aluno, de maneira clara e introdutória, os objetivos da aula, torna-se condição necessária para seu êxito final.

Realizamos como warmup uma atividade de interação a partir das imagens presentes na página introdutória do terceiro capítulo do livro. São quatro imagens: a primeira exibe uma deficiente visual com o seu cão-guia, a segunda apresenta um garoto em processo de recuperação de uma possivel fratura no braço, a terceira traz a relação entre mãe e filho e por fim a última imagem é composta por um casal de idosos. A partirdessas imagens, questionamososalunos: "What are the values associated with the pictures below? ${ }^{\prime \prime 15}$ e então criou-se um ambiente de conversa informal sobre o tema em questão. Após essas discussões iniciais, apresentamos um vocabulário (presente na página $50^{16}$ do livro) sobre situações de superação.

Percebe-se a estratégia de se utilizar de vários estilos de aprendizagem, levando em conta a visualização da escrita e a associação com imagens e frases. Paiva (2007) descreve as múltiplas inteligências (GARDNER, 1983) e as ações diversas para desenvolvermos nos alunos as estratégias de aprendizagem. A variedade de atividade aqui é de suma importância para a concretização do processo de aprendizagem. Ao se tratar do ensino de uma língua estrangeira, a associação com imagens facilita o entendimento.

d- Uso dos gêneros textuais e a formação crítica do aluno

O futuro professor deve conhecer a noção da variedade de gêneros textuais, que atravessam o muro da escola e são utilizados pelos alunos da escola básica para se comunicar. O uso de recursos além do promovido pelo livro didático se faz importante. Observamos esta variedade escolhida pelos alunos bolsistas e pela supervisora, como exemplificado abaixo:

$$
\begin{array}{ll}
1- & \text { Vídeo - História de Deiziane; } \\
2- & \text { Vídeo - About Team Work; } \\
3- & \text { Entrevistas (texto oral) gravadas em vídeos; } \\
4- & \text { Biografia de Irmã Dulce. }
\end{array}
$$

É inegável a quantidade de informação que foi socializada com os alunos. Este momento remete para a importância do debate e da reflexão crítica. $O$ acesso a um universo ampliado de fontes de informação de conhecimentos proporciona ao aluno maiores possibilidades de desenvolver sua criticidade. $\mathrm{O}$ debate de ideias e o confronto de argumentos, em uma sala de aula, proporciona uma democratização do conhecimento, pois segundo Costa (2012, p.922), “[...] a verdade é sempre relativa, matizada por pontos de vista, e deve ser compreendida dentro de um contexto

\footnotetext{
${ }^{15}$ Tradução nossa: Quais são os valores associados com as figuras abaixo?

${ }^{16}$ Esse vocabulário da página 50, também se conecta as imagens. Ex:Ambition - compation- courage - dedication friendship - integrity - optmism - overcoming
} 
determinado, em relação aos sujeitos envolvidos nas práticas letradas". Não podemos esquecer que o conhecimento é ideológico e que a neutralidade tende a ser uma utopia. O professor, neste sentido, deve transpor a linguagem e observar os valores, as crenças e as intenções por trás de uma leitura de um texto.

e- Atividades variadas:

1- Leitura dentro do conceito de pré-leitura, leitura e pós-leitura (TOMITCH, 2009);

2- Pesquisa através de entrevistas;

3- Apresentações das entrevistas;

4- Escrita na língua alvo;

5- Jogo demonstrativo para experimentar as dificuldades de outros.

A variedade de atividades é nítida durante toda a narrativa. Retiramos alguns trechos para exemplificar.

1- [...]Ao planejar as atividades com um tema tão significante, notamos a importância de trazer uma história de superação situada no contexto local dos alunos para exemplificar uma realidade próxima e contextualizar a temática trabalhada[...] 2-realizamos uma atividade de leitura proposta no livro didático que aborda a história do "Team Hoyt" (contexto global) [...] 3Depois da leitura do texto (página 52), realizamos as atividades do livro para consolidar as informações apresentadas no texto. Orientamos a leitura através de scanning para que os alunos encontrassem as informações específicas solicitadas nas atividades.

Quando o professor reflete sobre o seu planejamento deve pesquisar um bom número de atividades, pensando não só exclusivamente na motivação destes, como também em alcançar os diferentes tipos de aprendizes e este projeto reflete essa premissa.

f- Fechamento da atividade com reflexão e escrita na língua alvo

Como proposta de culminância a supervisora e os alunos bolsistas apresentaram as seguintes atividades:

1- Pesquisa através de entrevistas;

2- Apresentações das entrevistas;

3- Escrita na língua alvo (Apêndice A);

4- Jogo demonstrativo para experimentar as dificuldades vivenciadas outros. 
É muito difícil não ficar envolvido com o projeto após tantas etapas. As atividades 1 e 2 da culminância fazem os alunos perceberem as pessoas que fazem parte da escola, através das histórias de superação que foram socializadas para os discentes no ato das entrevistas. Isso remete novamente à reflexão durante a escolha do que vai ao "ar" para ser socializado com os seus colegas e tudo isso no universo da sala de aula onde esses mesmos alunos irão ouvir a socialização das outras entrevistas realizadas por seus colegas. Enfim, é um ato de reflexão, sensibilização e humanização do indivíduo promovido, com muita destreza, pela supervisora e os alunos bolsistas na implementação e culminância do projeto. Vejamos o trecho da narração de Miguel que evidencia esse envolvimento dos alunos de escola básica e bolsistas com o projeto:

O projeto, a partir de uma visão geral, foi um divisor de águas para os envolvidos, por razão do estudo das realidades difíceis que muitas pessoas enfrentam e ainda assim conseguem ultrapassar todos os obstáculos e viver como qualquer um. Em todo o momento do projeto, enfatizamos que talvez nossos problemas nem são tão grandes assim: é uma questão de saber lidar com as adversidades e ter força de vontade.

Essa sensação de envolvimento também foi sentida quando nós, coordenadoras, fomos vivenciaralgumas etapas de preparação do projeto. A qualidade em que o trabalho era conduzido pela supervisora mostrou-se de excelência. Do ponto de vista dos bolsistas, principalmente naquilo que se refere à sua formação enquanto profissional da educação, ter uma profissional atuando em seu ofício com responsabilidade e zelo, certamente irá servir de inspiração na construção de uma carreira vitoriosa.

\section{Considerações finais}

Ensinar leitura e escrita críticas em língua inglesa, nas escolas básicas, é romper com uma estrutura tecnicista imposta e vivenciada por gerações, que muito pouco ou nada fizeram para o processo de formação dos alunos. Podemos perceber que a realidade vivida nesta escola do interior da Bahia se reflete em muitos outros lugares. A narrativa de Miguel expõe que é possível provocar mudanças e que elas devem ser perpetuadas no ambiente escolar, porque elas, de fato, funcionam. Contudo, esta atitude deve contaminar a todos os profissionais envolvidos com educação e que desejam proporcionar um ensino de qualidade, que tenha como premissa uma educação críticoreflexiva.

Trabalhar com o ensino de língua inglesa e a formação do letramento crítico não são tarefas fáceis, requer tempo, desconstrução e reconstrução de significados. Requer repensar quem somos e o que desejamos ser como professores de línguas. Consequentemente, exige do professor e futuro professor, no seu processo contínuo de formação, muito conhecimento, leitura e reflexão. Neste 
sentido, o exercício deste repensar, não tem fim, e não obstante exige uma habilidade reflexiva que muitos futuros professores ainda não possuem, por talvez nunca terem sidos expostos a reflexão ou ainda estão em processo de amadurecimento como futuros profissionais.

Percebemos, de forma viva na narrativa de Miguel, o trabalho empenhado pelos bolsistas e a supervisora na condução de várias etapas no planejamento desenvolvido. Os resultados alcançados por estes, diante das respostas dos alunos da escola básica, de acordo com Miguel foi "um divisor de águas para os envolvidos".

Diante deste quadro, percebemos o valor do planejamento e da pesquisa.Supervisora e alunos bolsistas buscaram ir além do livro didático. Ao coletar letramentos alternativos, como vídeos, imagens e textos significativos, os envolvidos no projeto proporcionaram as condições básicas e necessárias pararepensar de forma crítica a sociedade e seus valores. A variedade de atividades, ainda contribuiu de forma significativa não só para a formação do conhecimento na língua alvo, como também abrindo portas para a autorreflexão como cidadão consciente da sociedade ao seu redor.

\title{
Analysis Of A Narrative Based On Teaching Reading And Writing In English Language
}

\begin{abstract}
:
This experience report aims to present the result from a project of teaching and learning about reading and writing in English language (LI), developed under the PIBID of UNEB / Campus XIV in Conceição do Coité city in the state of Bahia. The project was implemented in two public institutions of basic education in the region. The main motivation for the execution of this project was the identification, through researches in graduation end productions, of the grammatical focus as the only methodology used in the classroom in the basic schools of the region. In this sense, we propose an intervention of PIBID that had as one of the objectives to reflect on the teaching of writing and reading in LI based on critical literacy, through the narrative of the graduation student Miguel Gordiano Ramos.
\end{abstract}

Palavras-chave: PIBID 1. Teacher training 2.Teaching reading and writing 3.Englishlanguage4.

\section{Referências}

COSTA, ElzimarGoettenauer de Marins. Práticas de Letramento crítico na formação de professores de línguas estrangeiras. In: Revista de linguística aplicada, v.12,n.4, 2012- Belo Horizonte, MG. Faculdade de Letras da UFMG.il. ; $22,5 \mathrm{~cm}$.

GARDNER, H. Frames of mind: the theory of multiple intelligences. New York: Basic Books. Basic Books paperback, 1983. 
GIROUX, Henry A. Professorescomointelectuaistransformadores. In: GIROUX, Henry A. Os professores como intelectuais: rumo a uma pedagogia crítica da aprendizagem.Trad. de Daniel Bueno. Porto Alegre: Artmed, 1997. p. 157-164.

HARMER, Jeremy. The Practice of Language Teaching. New York: Longman Publishing, 2000. JANZEN, Joy. Teaching strategic reading. In: RICHARDS, J. C; RENANDYA, W. A. (Orgs). Methodology in language teaching: An anthology of current practice. New York: Cambridge Universitypress. 2009, p. 287-294.

JORGE, Miriam Lúcia dos Santos. Preconceito contra o ensino de língua estrangeira na rede pública. In: LIMA, Diógenes Cândido de. (Org.). Ensino e aprendizagem de língua Inglesa: Conversas com especialistas.São Paulo: Parábola editorial, 2009, p.161-168.

MOTTA, Taíse Figueira. Leitura em inglês no Ensino Médio: uma análise da atividade de leitura na escola e sua relação com a comunicação mediada pelas novas tecnologias. Dissertação (Mestrado em Estudos linguísticos e literários em inglês), Faculdade de Filosofia, Letras e ciências humanas, USP, São Paulo (SP), 2007, 181f.

OLIVEIRA, Luciano Amaral. Aula de inglês: do planejamento à avaliação. São Paulo: Parabola Editorial. 2015.

PAIVA, V. L. M. de O. Desenvolvendo a habilidade de leitura. In:PAIVA, V. L. M. de O (Org.). Práticas de ensino e aprendizagem de inglês com foco na autonomia. Campinas: Pontes Editores. 2007, p. 129-148.

RAIMES, Ann. Ten Steps in planning a writing course and training teachers of writing.In: RICHARDS, J. C; RENANDYA, W. A. (Orgs).Methodology in language teaching: An anthology of current practice. New York. Cambridge Universitypress. 2009, p. 306-314.

SILVA, I. M. da; JORGE, M. L dos S. Alguns princípios do ensino da escrita. In:PAIVA, V. L. M. de O (Org.). Práticas de ensino e aprendizagem de inglês com foco na autonomia. Campinas: Pontes Editores. 2007.

SILVA, Elizabeth Maria da. Letramento: um fenômeno plural. In: Revista de linguística aplicada, v.12,n.4, 2012- Belo Horizonte, MG. Faculdade de Letras da UFMG.il. ; 22,5 cm.

TELLES, J. “É pesquisa é? Ah, não quero, não, bem!”: Sobre pesquisa acadêmica e sua relação com a prática do professor de línguas. Linguagem e Ensino. Universidade Católica de Pelotas, RS. v.5, n. 2, p. 91-116, 2002.

TOMITCH, L. M. B. Aquisição da leitura em língua inglesa. In: LIMA, Diógenes Cândido de. (Org.). Ensino e aprendizagem de língua Inglesa: Conversas com especialistas.São Paulo: Parábola editorial, 2009, p. 191-201. 


\section{Apêndice A}

\section{Student A}

In an interview with the student Maria Daniele, she told us her story of overcoming. When she was 15 , in 2014 , his father took a horse kick on the left chest, which caused severe damage leading him to death injury. After the death of his father, Dani starts to participate more of rodeos, apartheid parties, ringlets and handles oxen, that sports her father used to practice. Dani also tells us that although this sport quite remember her father, she is not sad, because for her it is very important to remember it.

\section{Student B}

In an interview with the student PolianaMascarenhas de Abreu, she told us that a friend suffered a motorcycle accident and had head trauma. The injury occurred by a strong trauma to the head because he was not wearing the helmet. Very sad about what happened, she and a classmate began to think of a way to avoid this to happen again. They studied a lot and created a project called "Helmet Saves Lives". She explains that the bike has a device that connects to another in the Helmet, staring the bike only when a Button on the Helmet is pressed, this forcing the piioto to wear it, avoiding strokes on the head if an accident become to happens.

\section{Student C}

In an interview with the student Maria Daniele, she told us her story of overcoming. When she was 15, in 2014, his father took a horse kick on the left chest, which caused severe damage leading him to death injury. After the death of his father, Dani starts to participate more of rodeos, apartheid parties, ringlets and handles oxen, that sports her father used to practice. Dani also tells us that although this sport quite remember her father, she is not sad, because for her it is very important to remember it. 